\title{
Las perífrasis verbales de infinitivo en el español de los niños de La Mar (Ayacucho)
}

\author{
The verbal periphrasis of infinitive constructions in the Spanish of children in La \\ Mar district (Ayacucho Region) \\ Jorge Esquivel Villafana \\ Universidad Nacional Mayor de San Marcos \\ Contacto: esquivel_jorge5@hotmail.com

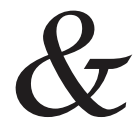

Resumen

El presente estudio se centra en la descripción de las construcciones perifrásticas verbales de infinitivo registradas en el español de los niños del distrito de La Mar (Ayacucho), zona andina de contacto de lenguas quechua-español, ubicada en el sur del Perú. Dada la naturaleza del trabajo, este será de corte sintáctico-semántico.

Palabras clave: Sintaxis-semántica, español andino, perífrasis verbales

Abstract

The current study focuses on the description of verbal periphrasis of infinitive constructions in the Spanish of children in La Mar district (Ayacucho Region), an Andean area of Spanish and Quechua languages in contact, located in the South of Peru. Given the nature of the research, this will be of syntactic and semantic type.

Keywords: Syntax-semantic, Andean Spanish, verbal periphrasis

Recibido: 23/5/16. Aceptado: 15/7/16

\section{Introducción}

En el presente trabajo, nos proponemos describir las perífrasis verbales de infinitivo utilizadas por los niños de distrito de la Mar (Ayacucho), zona andina de contacto bilingüe quechua-español -en ese orden de adquisición de las lenguas-, ubicada en la sierra sur del Perú

De hecho, se parte de la consideración de que las construcciones perifrásticas verbales en el español de una zona de contacto de lenguas 
Jorge Esquivel Villafana

presentan ciertas características peculiares determinadas por el influjo de la lengua materna, el cual las afecta en todas los niveles de la lengua y les da una fisonomía y usos particulares a veces muy ajenos al español general. De aquí que nuestro estudio se centre en la atención de las estructuras perifrásticas del tipo no personal de infinitivo desde el nivel morfosintáctico de la lengua.

\section{Metodología}

\section{Objetivo}

Nos proponemos como objetivo general describir las construcciones perifrásticas en relación con los significados que las caracterizan como producto de un español infantil en un contexto bilingüie.

\section{Hipótesis}

Partimos de la hipótesis de que las construcciones perifrásticas verbales empleadas por los niños del distrito de la Mar (Ayacucho) evidencian una divergencia estructural y semántica características en relación con el español estándar.

\section{Metodología y corpus}

El presente estudio corresponde a una investigación de corte descriptivo. El corpus base comprende veinte horas de grabación de conversación espontánea de niños de ocho a doce años de edad del distrito de La Mar (Ayacucho) reunidas durante el verano del año 2015.

La perífrasis verbal, término muy utilizado entre los especialistas del lenguaje en el abordaje de la temática de frase verbal o predicado, resulta a veces conflictivo en su definición y en la determinación de su estructura formal. Gili Gaya, por ejemplo, citado por HoŠŠo (2008, p. 7) la considera simplemente como una frase verbal más; tal determinación encuentra justificación en su lógico correlato con las estructuras frasales denominadas frases nominales, adjetivas, verbales preposicionales, adverbiales y conjuntivas. Carratalá, citado también por HoŠŠo (2008) prefiere denominarla "frase verbal con verboide". Para 
establecer la diferencia entre una frase verbal con verboide y una construcción de verbo con verboide, que incluso pueden coincidir formalmente, asevera que cuando se trata de "frase verbal con verboide", se está en una construcción donde ambos verbos funcionan como una unidad estructural sin jerarquía alguna entre sus componentes, pues "ninguno de los verbos desempeña una función complementaria o coordinadora con respecto al otro". Por ello, en (1) no se la puede segmentar en dos componentes independientes, "deben" + "salir", con significados independientes, sino considerarla como un bloque unitario donde el primer verbo se desemantiza en favor de la unidad.

Ellos deben salir pronto.

En cambio, en (2), la estructura verbal es analizada como una construcción de "verbo con verboide" donde, independientemente de las sendas predicaciones de los verbos considerados individualmente, se establece entre ellas una relación de subordinación sintáctica de verbo-complemento: fumar se constituye en el complemento, fácilmente segmentable, del verbo transitivo "desea".

(2) Ella desea jugar.

La RAE (2010, p. 529), por otro lado, asume la concepción del término perífrasis verbal como una combinación sintáctica de verbo auxiliar más verbo auxiliado; este último de forma no personal, también reconocido como verbo principal, pleno, puede estar en infinitivo, gerundio o participio, "sin tener que dar lugar a dos predicaciones distintas: 'No puedo entrar'; 'Iremos considerando cada caso particular'; 'llevo escritas diez páginas', etc.".

Gómez Torrego (2011), siguiendo la línea analítica sugerida por la RAE, añade que el primer verbo de la perífrasis verbal, llamado auxiliar, es el que comporta las informaciones morfológicas de número y persona, y se conjuga en todas (o parte de) las formas o tiempos de la conjugación. Según la estructura morfológica del otro verbo que puede aparecer en infinitivo, gerundio o participio, se hablará de perífrasis verbal de infinitivo, gerundio o participio 
Jorge Esquivel Villafana

respectivamente.

De hecho, lo relevante en la concepción de construcción perifrástica es la incapacidad de segmentarse en componentes independientes con diferentes predicaciones. Independientemente del número de elementos que la conforman, "toda la construcción es analizada como unidad, como el núcleo verbal de un predicado" (Gómez T., 2011: 193), como ocurre con los ejemplos de (3).
a. Tenemos que dibujar.
b. Puede ser el director.
c. Debió salir temprano.
d. Tiene que ganar.

Desde la perspectiva de la semántica, se considera que el carácter monolítico de una construcción perifrástica no estriba en su incapacidad de segmentarse en componentes con diferente jerarquía, auxiliar y auxiliado precisamente, sino en el valor agregado de su significado, el cual , en principio, no constituye el resultado de la suma de los significados de sus componentes, sino que, por el contrario, adopta un matiz particular que lo proyecta hacia una significación secundaria determinada por la pérdida del rasgo semántico denotativo del verbo auxiliar en aras de una connotación global, lo que advertimos en la construcción perifrástica de la oración (4).

(4) Sotil llegó a jugar por el Barcelona.

El significado original, básico, denotativo del verbo "llegó", reconocido como verbo de movimiento, pierde su valor original para dar lugar a un nuevo significado como "tener capacidad de", "haber sido capaz de un hecho", etc. Asimismo, en la oración (5), la construcción perifrástica subrayada muestra el verbo auxiliar "tenía" con un significado diferente al de tener, o ser poseedor de algo (tenía una bicicleta); en realidad, dado el contexto, este cobra el valor agregado de "obligación”, "necesidad”, etc.

(5) Ella tenía que llegar a las ocho de la noche. 
Lo que no ocurre, sin embargo, en una construcción no perifrástica

(6) Olga prometió regresar pronto.

En ella, el verbo "prometer" conserva su significado básico, original, denotativo de "decir a alguien que hará o dirá cierta cosa, comprometiéndose u obligándose a ello; asegurar o confirmar la certeza de lo que se dice."

(Larousse, 2012).

Técnicas de reconocimiento. En el análisis riguroso de las construcciones verbales, se hace uso de una serie de pruebas de carácter sintáctico algunas (I, II, III, IV, y V) y de valor semántico otras (VI y VII) (Gómez T., 1999; HoŠŠo, 2008), con la finalidad de determinar con un alto grado de certeza la posibilidad o no de su carácter perifrástico.

La prueba de la conmutación.- Según esta, un verbo de forma no personal puede formar con un verbo conjugado una construcción perifrástica. $\mathrm{Si}$ en ella el verbo no personal (infinitivo, gerundio o participio) puede ser sustituido por un nombre, pronombre o adverbio, estas formas no constituyen perífrasis verbal.

(7) a. Olga tiene que pegar los afiches.

Lucía piensa salir temprano.

Obsérvese que en (7a), los verbos involucrados en la construcción verbal conforman una perífrasis verbal, pues no es posible la sustitución del verbo de forma no personal por un pronombre:

(8) *Olga lo tiene.

En cambio, en (7b), la forma verbal involucrada en la construcción no hace perífrasis, puesto que el verbo de forma no personal sí puede ser sustituido por lo:

(9) Lucía lo piensa.

Prueba de la interrogación.- Esta se remite a la imposibilidad de transformar el verbo de forma no personal en una forma pronominal interrogativa, tal que puede ser el "qué" en las construcciones perifrásticas. Considérese la oración (7a) reescrita como (10): 
Jorge Esquivel Villafana

Olga tiene que pegar los afiches.

Si aplicamos en ella la transformación de la forma no personal por el interrogativo qué en la construcción perifrástica, obtenemos (11), la cual resulta una oración agramatical, pues su significado no se corresponde con el sentido original de la oración.

(11) * ¿Qué tiene Olga?

En cambio, no ocurre lo mismo si aplicamos el mismo proceso de la prueba de la conversión interrogativa a la construcción no perifrástica (7b), aquí reescrita como (12).

(12) Lucía piensa salir temprano.

De la aplicación de esta prueba, resulta (13), una oración interrogativa convencional cuya respuesta alude a la forma no personal original.

¿Qué piensa Lucía?

Con verbos meteorológicos y existenciales como auxiliados.- Según esta prueba, resultan perifrásticas aquellas construcciones conformadas por verbos meteorológicos y existenciales, esto es, aquellos verbos que, por naturaleza léxica, carecen de sujeto:

a. Debe haber.

b. Puede llover.

IV. Selección del sujeto y de los complementos por parte del auxiliado.- En esta prueba, se asume que solo el verbo de forma no personal de una construcción perifrástica puede seleccionar los elementos argumentales de la oración, sujeto y complementos verbales. El primer verbo o auxiliar actúa simplemente como apoyo gramatical para el desarrollo del segundo, como se aprecia en (15).

a. Luisa suele obsequiar dulces a sus amigas.

b. José quiere comprar flores.

En (15a) el verbo "soler" de la perífrasis "suele obsequiar" carece de la capacidad de seleccionar sus propios argumentos, pues no selecciona el tema "dulces" ni el dativo "a sus amigas", capacidad que sí se puede atribuir al verbo "obsequiar", cuya red semántica alcanza a seleccionar el tema "dulces" y el dativo "a sus 
amigas", pues se obsequia algo a alguien., como se aprecia en (16):

(16) Luisai suele [PROi obsequiar dulces a sus amigas]

V. Formación de estructuras pasivas.- Según esta prueba, una construcción perifrástica nunca pasiviza el primer verbo o auxiliar; con las construcciones no perifrásticas ocurre lo contrario: pasivizan el verbo auxiliar y no la forma no personal. Considérese las oraciones (17).

a. Luisa tiene que escribir cartas.

b. Prometió escribir cartas.

De la aplicación de la transformación de pasivización a las oraciones (17), se obtiene sus correspondientes (18).

a. *Escribir cartas es tenido por Mónica.

Escribir Cartas fue prometido por Mónica.

VI. Gramaticalización del verbo auxiliar.- De acuerdo con esta prueba, en una construcción perifrástica, el primer verbo o auxiliar, pierde o desvía parte de su significación, se desemantiza en favor del verbo de forma no personal.

(19) Tiene que dormir.

En la oración (19), el verbo "tener" tener pierde su significado denotativo de posesión o propiedad de algo. El significado final no depende del verbo "tener" ni de "dormir", sino de toda la construcción.

VII. El auxiliar como verbo conceptual.- Según esta prueba, la mayoría absoluta de los verbos que funcionan como auxiliares (20) pueden aparecer también fuera de la perífrasis como verbos conceptuales (21):

a. Hay que luchar.

b. Debe estudiar.

a. Hay muchos invitados.

b. Me debe diez soles.

Los únicos verbos que siempre deben ir acompañados de otros verbos son los verbos soler y poder.

De todas estas pruebas diseñadas para determinar el carácter perifrástico o no de una construcción con dos o más verbos, parecen ser las de 
carácter sintáctico las que han ganado mayor aceptación y que han permitido incluso, la definición más usual: la perífrasis verbal como construcción que funciona en conjunto como un solo predicado verbal, como una unidad sintáctica.

\section{Clases de perífrasis}

A) Según el tipo de fusión con el verbo de forma no personal, pueden ser:

i. Directas.-Cuando carece de elementos prepositivos o conjuntivos:
a. Debe jugar.
b. Suele nevar.

ii. Indirectas.- Cuando los verbos se relacionan mediantes nexos prepositivos o conjuntivos:
a. Comenzó a garuar.

b. Tiene que salir.

Según la estructura morfológica del verbo no personal.- De acuerdo con la estructura morfológica del verbo de forma no personal, pueden ser:
a) perífrasis de infinitivo
b) perífrasis de gerundio
c) perífrasis de participio

\section{Las perífrasis verbales en un español andino}

Las construcciones perifrásticas del español general adquieren en un contexto de contacto de lenguas una particular fisonomía dada la fuerte influencia de la lengua materna, la cual las afecta en los aspectos morfosintáctico y semántico, dando como resultas, en algunos casos, construcciones muy particulares, singulares, de carácter regional con empleos un tanto ajenos al español general. Para los propósitos de esta presentación, ceñiremos nuestro estudio solo a la descripción de las construcciones perifrásticas de infinitivo e incluiremos en ella las construcciones perifrásticas más características. 
Clasificación. Las construcciones perifrásticas de infinitivos se suelen clasificar en modales y aspectuales.

A. Las perífrasis modales.- Son aquellas construcciones en las que el evento significado por la forma no personal del verbo en infinitivo es presentado como algo obligatorio, necesario. Estas pueden ser

$<$ deber que + infinitivo $>$

$<$ hacer + infinitivo $>$ o las construcciones causativas

$<$ haber que + infinitivo $>$

$<$ poder + infinitivo $>$

$<$ tener que + infinitivo $>$

La perífrasis < deber + infinitivo $>$.- Esta es utilizada para expresar obligación de la acción denotada por el verbo en infinitivo:

(24) a. Mi mamá me dice sacan granizada y deben decir en quechua: "Ándate granizada".

b. Nuestro toro escapa, nosotros debemos buscar...

Con negación, cobra sentido la necesidad de mostrar obediencia.

(25) a. Los niños no deben hacer desorden

b. orque los niños no deben tomar.

$<$ Hacer + infinitivo $>$ o las construcciones causativas.- Las construcciones perifrásticas causativas conformadas por el verbo "hacer" + infinitivo, de escaso empleo en el español general, aparecen sin embargo, recurrentemente, en las variedades andinas. Cerrón Palomino, citado por De Granda (2001, p. 63), las describe como parte del habla motosa peruana restringida solo a determinadas construcciones (hacer morir, hacer ver, hacer seguir) y que, por supuesto, detentan una matriz estructural quechua. De acuerdo con De Granda (2001, p.163), estas construcciones "son propias de zonas de contacto linguístico, como ocurre en el noroeste y nordeste argentinos, donde las lenguas en 
Jorge Esquivel Villafana

relación de contacto con el español son el quechua y el guaraní respectivamente".

El español de la variedad que analizamos presenta singulares formas morfosintácticas a todas luces ajenas al español general y la amplia gama de verbos involucrados en ellas rebasa las restricciones referidas líneas arriba:

a. El profesor es bueno, nos hace enseñar (nos enseña), nos hace explicar (nos explica).

b. Eso te puede hacer morir (matar) a ti propia.

c. El maíz hacemos moler (molemos) para alimentarnos.

En esta variedad de español, tampoco es infrecuente los hallazgos de alternancia de las construcciones compuestas con las causativas en la misma oración:

(27) a. Esto nos ha enseñado, así nos hacía enseñar.

b. Han agarrado una niña; cuando le han cortado, lo han hecho morir.

Es a través del fenómeno del calco sintáctico, como consecuencia del contacto linguiístico quechua-español, en ese orden de adquisición de las lenguas, como se muestra en gran parte la influencia del patrón estructural quechua en las construcciones perifrásticas causativas del español regional.

Así en el quechua, el morfema verbal -chi, de valor causativo, puede significar, según Soto (1993, p. 339), 1. Que el sujeto motiva o causa una acción que es ejecutada por otro: manam kasuwarqachu chaymi maqachirqani 'no me obedeció, por eso le hice castigar'. [...] 2. Que el sujeto permite realizar una acción a otra: qawachisaq wasiyta payman 'le haré ver mi casa a él'.

El sufijo -chi tiene la propiedad de convertir los verbos transitivos (o intransitivos) en formas verbales causativas. Véase, por ejemplo, el análisis de la formación de causativas a partir de los verbos "timpu-“('hervir') y “qaway” ('ver'), propuesto por Lara (2007, p. 262):

Raíz verbal sufijo sufijo equivalente

Causativo futuro


Las perífrasis verbales de infinitivo en el español de los niños de La Mar

$\begin{array}{llll}\text { timpu- } & \text {-chi } & & \text { 'hacer hervir' } \\ \text { timpu- } & - \text { chi } & -k u & \text { 'hacer hervir algo' } \\ \text { timpu- } & - \text { chi } & -s a q & \text { 'haré hervir' } \\ \text { qaway- } & \text { chi } & & \text { 'hacer ver' }\end{array}$

Lo mismo que ocurre con los verbos intransitivos como 'puñu- ('dormir'):

puñu- -chi 'hacer dormir'

De este modo, la traducción literal de la oración runtam qawachi Carlos wawqenman ('Carlos muestra los dientes a su hermano') daría como resultas la estructura literal causativa 'los dientes hace ver Carlos a su hermano'.

Por su parte, Escobar y Wölk (2009), análogamente, describen las producciones "hacer ver", "hacer quemar", "hacer mojar" del español de los bilinguies ticunas, como producto de un proceso de calco sintáctico cuyas formas básicas corresponderían a las expresiones ticunas "wi -ee", "ba -ee" en las que la base verbal está formada por la raíz verbal y el morfema de causativo, como en el quechua.

De Granda, (2001, p. 163), por otro lado, sostiene que en el español paraguayo, la abundancia de las expresiones causativas, como "hago calentar el agua" o "él hace decir", si bien son bastante divergentes de sus equivalentes del español general, constituyen formas que devienen básicamente, por calco sintáctico, de las formas guaraníes "ambyaku” y "he iuka”; añade que lo mismo puede aplicarse "mutatis mutandi en relación con estructuras sintácticas quechuas, a las construcciones del mismo tipo existentes en el área noroeste del país argentino.

Escobar (2000: 128) por su parte, expresa que en las zonas bilingües de español en contacto con el quechua, la expresión causativa hacer + infinitivo se encuentra entre las formas perifrásticas más empleadas con función aspectual, lo que lo evidencia con el ejemplo de Schumacher (1975):

(28) Me voy a hacer comprar cometa para aprender hacer volar.

La perífrasis $<$ haber que + infinitivo $>$.- Esta construcción perifrástica expresa 
Jorge Esquivel Villafana

el valor modal de obligación, necesidad o conveniencia referido a un sujeto impersonal. Según Gómez Torrego, (1999, pp. 3357-8), la construcción "haber que" engloba el valor de encubridor de actores, idéntico al de la partícula "se" de construcciones unipersonales, cuyo valor es también el de encubridor de actores. Así, la oración

(29) Hay que inventar una historia.

Es equivalente a "se tiene que inventar una historia".

En el corpus que analizamos, hallamos que esta construcción perifrástica suele darse con construcciones subordinadas completivas donde la secuencia "hay que + infinitivo" funciona como la completiva-OD del verbo decir en sus diferentes conjugaciones. En este contexto, ella adquiere el significado de obligación o necesidad equivalente a "tenemos que" o "vamos a":

a. Mi tía cuando traigo algo de comida me dice: "Hay que jugar".

(Mi tía cuando traigo algo de comida me dice: "Vamos a jugar")

b. Mi tía a mi mamá también ha dicho: "Hay que ir a Parque de Leyendas".

(Mi tía a mi mamá también ha dicho: “Tenemos que ir al Parque de las Leyendas")

c. Y después mis primitos me dicen: "Hay que jugar".

(Y después mis primitos me dicen: "Vamos a jugar")

La perífrasis < poder + infinitivo > - En la variedad que analizamos, esta suele ser muy recurrente y poseer varias posibilidades de significación, entre ellas: 1) posibilidad de que pueda ocurrir algo, (31a); 2) eficacia para hacer algo o la incapacidad de hacerlo (31b); o 3) la incapacidad de realizar el evento cuando la perífrasis va precedida de una negación (31c, d).

(31) a. Así, tan de cerca, te puede tirar piedra (la jarjacha).

b. Yo sé cómo pueden agarrar zorro... con soga.

c. Como no podía estudiar el niño, lo han botado.

d. Pero, por su pelaje, no puede vivir en San Miguel (la alpaca).

En oraciones interrogativas, esta secuencia perifrástica puede expresar 
el valor significativo de solicitar el permiso para la realización de una acción:

a. ¿Me lo puedes comprar helados, por favor?, dijo.

b. ¿Puedo ir a miccionar?, dice.

En el corpus que analizamos, encontramos, particularmente, que con la secuencia perifrástica conformada por el verbo poder en presente del subjuntivo, "pueda" más el verbo en infinitivo, precedida de la locución conjuntiva 'para que', se expresa la capacidad de una acción referida al momento actual o al futuro inmediato; en el empleo de esta perífrasis se sustituye la forma del presente del subjuntivo del verbo subordinado en el español general por un verbo principal perifrástico en infinitivo.

a. Les digo para que puedan traer a otros amiguitos.

(Les aconsejo que traigan a otros amiguitos.)

b. Les digo para que puedan contar unas historias.

(Les aconsejo que cuenten otras historias.)

La perífrasis < tener que + infinitivo>.- Esta construcción perifrástica expresa la obligación, necesidad o propósito. En el corpus que analizamos, encontramos el predominio del significado de necesidad de la realización de una acción.

(34) a. Lo fríes la papa, le echas la zanahoria, cebollas. La carne lo fríes y le echan vinagre y sillao un poquito. Sal y arroz tengo que cocinar.

b. Yo tengo que lavar mi ropa.

c. A veces mi mamá no me deja (salir) porque tengo que hacer mi tarea.

d. A veces cuando la cabra se va, tienes que seguir y traerlo.

La perífrasis <venir a + infinitivo>.- Es una construcción que mantiene el significado de solicitud del traslado de alguien de cualquier lugar hacia el lugar donde está el que habla en términos de una orden o deseo (Larousse, 2012). Es una perífrasis de escaso uso en el corpus que analizamos.

(35) Jerry, ven a comer, diciendo Rubí, vengan a comer.

Perífrasis aspectuales.- De acuerdo con la normativa, son consideradas aspectuales las siguientes construcciones perifrásticas:

$<$ comenzar a + infinitivo $>$ 
Jorge Esquivel Villafana

$<$ empezar a + infinitivo $>$

$<$ ir + infinitivo $>$

$<$ terminar de + infinitivo $>$

$<$ volver a + infinitivo $>$

La perífrasis < comenzar a + infinitivo >.- En esta variedad de español, esta perífrasis conserva el valor normativo referido al inicio de algo, dar principio de algo. Esta perífrasis regularmente muestra la omisión de la preposición a:

(36) a. El sembrado se lo lleva por dentro de tierras y comienza ( ) hacer huequito y se echa el trigo.

b. Mi madre entonces nos da (libro) a nosotros para comenzar a leer y escribir

La perífrasis <empezar a + infinitivo>.- En esta variedad, suele significar el inicio de una acción denotada en el verbo en infinitivo del cual no se precisa el término, simplemente continúa:

a. ... maíz empieza a cargar, después de allí paseamos.

b. Después empiezan a bailar, se ponen talco en su casa...

c. Franklin se molesta, le pega y después empieza a llorar.

d. Y de allí empiezan ( ) aplaudir cantando.

e. La gente baila, mueven la yunsa, después empiezan a cortar con hacha.

El adverbio "después" suele acompañar a esta perífrasis para delimitar el final de la acción precedente y el inicio de la descrita por la perífrasis en una secuencia narrativa, en clara relación con su carácter aspectual.

Encontramos también, en esta variedad, que el verbo auxiliar de la perífrasis empezar a + infinitivo suele aparecer auxiliado por el presente del verbo "haber" (ha) para dar la forma compuesta del auxiliar (ha empezado) + el infinitivo -estructura utilizada para expresar en una narración la anterioridad de la acción con referencia al momento presente y que puede ser de carácter durativo: 
(38) a. Le he da'o, le decía, lapazazo y después se ha empezado a llorar.

b. Entonces su mamá ha empezado a gritarse.

La perífrasis <ir + infinitivo>.- Una de las modalidades perifrásticas más recurrentes en esta variedad dialectal es la secuencia del pretérito imperfecto del indicativo del verbo ir (iba) + un verbo en infinitivo, con el valor significativo de pretérito narrativo o de la narración de un acto intencional:
a. Ese su esposa iba (a) envenenarlo a mi hermano.
b. Iba ir mi mamá abajo a buscarlo.
c. Íbamos ir al monte a buscar.
d. Sí, a la chacra iba a traer maíz.

Las secuencias perifrásticas de las formas de ir (vas, va, vamos, etc.), formas conjugadas del presente de indicativo del auxiliar, más el verbo en infinitivo, son utilizadas para expresar el valor temporal de futuro cercano, casi inmediato:
a. Y el otro... otro ya va hacer un lectura.
b. La profesora nos va a tomar examen de comunicación.
c. Hablan la gente diciendo "Vamos a contar de esos ratero..."
d. Con soga va a amarrar oveja.

Es también característico de esta variedad el empleo del presente del indicativo (vas) por el presente del subjuntivo (vayas) en la expresión de la prohibición de secuencias reproducidas literalmente que provienen de eventos recientes, de pasado inmediato:

a. No me vas (vayas) pedir tal cosa, así me dice (dijo).

b. "No, no vas (vayas) a jugar con ella", así mi tío dice (dijo).

En esta variedad linguística, la secuencia perifrástica <voy a ir >, empleada, preferentemente, para expresar el tiempo futuro de una acción, en detrimento de la forma simple "iré", suele adquirir el carácter de pronominal, pues casi siempre se halla acompañada de un pronombre variable; incluso, puede aparecer con reduplicación de pronombres:

a. Yo, en vacaciones, me voy a estudiar en Ayacucho. 
Jorge Esquivel Villafana

b. Después la puma ha dicho: "Voy a irme a pasear un rato".

c. Y a nosotros nos dijo diciendo: "No me voy a quedarme yo en acá”.

d. "Ya no te voy a molestarte ya", diciendo chau se ha ido.

La perífrasis <terminar de + infinitivo>.- Esta construcción perifrástica expresa el límite de una sucesión de hechos que llega a su fin y, generalmente, se conecta con otras formas verbales que indican acciones en tiempo presente:

(43) Ellos terminan de comer, de bailar, de cantar, se tiran y corretean por allá, por el monte.

Precisamente, su empleo con verbos conjugados en tiempo presente le da un valor de continuidad de acciones inmediatas. La presencia de la conjunción adverbial 'cuando', que encabeza la proposición subordinada refuerza el valor de pretérito de las acciones referidas por el verbo.

(44) a. Y cuando terminan de sembrar, cocina y comen.

b. De allí a ellos preguntan para qué cantan cuando terminan de cantar.

La perífrasis < volver a + infinitivo > - Esta construcción perifrástica apela al significado de reiteración de una acción realizada. En el ejemplo que ilustra el caso, se alude a una acción que se ha realizado de modo incompleto o mal, por lo que se solicita que se repita el proceso de modo que el final resulte más adecuado. En el corpus que analizamos, esta forma perifrástica tiene escasa presencia.

(45) iNo te has bañado!, me dice. iVuelve a bañarte, bien limpiecito!

\section{Conclusiones}

A manera de conclusión, nos permitimos presentar este considerando tanto sus formas modales como aspectuales.

1. En cuanto al empleo de las formas modales del infinitivo, encontramos las siguientes

\section{Características:}

a. Las construcciones causativas conformadas por el verbo $<$ hacer + infinitivo >, consideradas de escaso empleo en el español general, aparecen, sin 
embargo, con mucha recurrencia en esta variedad, lo cual se constituye en la característica de esta variedad de español con relación al restringido número de casos registrados en otras variedades regionales.

El profesor es bueno, nos hace enseñar nos hace explicar.

(El profesor en bueno nos enseña y nos explica (los temas))

Tampoco es infrecuente el hallazgo de alternancia de las construcciones compuestas con las causativas en la misma oración:

Esto nos ha enseñado, así nos hacía enseñar.

b. La perífrasis $<$ hay que + infinitivo $>$, en función de completiva del verbo "decir" en sus diferentes conjugaciones, cobra el significado de obligación o necesidad:

Mi tía, cuando traigo algo de comida, me dice: "Hay que jugar".

(Mi tía, cuando traigo algo de comida, me dice: "Vamos a jugar.)

c. La perífrasis < poder + infinitivo > se constituye en la más recurrente en esta variedad, pues presenta una variedad de posibilidades de significación. Esta perífrasis suele sustituir la forma del presente del subjuntivo del verbo subordinado en el español general:

"Les digo para que puedan traer a otros amiguitos".

(Les aconsejo que traigan a otros amiguitos.)

2. En cuanto al empleo de las perífrasis aspectuales, encontramos que la construcción <ir + infinitivo > muestra una supremacía absoluta con respecto al de las otras formas aspectuales; ello, dadas las diferentes formas de conjugación en que suele aparecer el verbo ir (va, voy iba, etc.).

\section{Referencias bibliográficas}

De Granda, G. (2001). Estudios de linguiística andina. Lima. Fondo editorial de la Pontificia Universidad Católica del Perú.

Escobar, A. M. (2000). Contacto social y linguístico. El español en contacto con el quechua en el Perú. Lima, Fondo Editorial de la Pontificia Universidad Católica del Perú. 
Jorge Esquivel Villafana

Gómez Torrego, L. (1999). Los verbos auxiliares. Las perífrasis verbales de infinitivo. En Real Academia Española, Gramática descriptiva de la lengua española. Madrid, Espasa Calpe S.A.; pp. 3322-3390.

Gómez Torrego, L. (2011). Gramática didáctica del español. España, Ediciones SM.

Hoššo, M. (2008). Perífrasis verbales en la prensa española deportiva. República Checa, Universidad Massaryk.

Lara I., E. (2007). Manual de quechua. Enseñanza-aprendizaje. Lima, Lluvia Editores.

Larousse Editorial (2012). El pequeño Larousse ilustrado. Barcelona, Larousse Editorial.

Montes R., M. M. (2009). Español de contacto, español andino y español amazónico: estudios de caso en comunidades sikuani, wayú y tikuna. En Escobar, A. M.; Wölk, W. (eds.) Contacto linguiístico y la emergencia de variantes y variedades linguísticas. Madrid, Iberoamericana; pp. 93125.

Real Academia Española (1999). Gramática descriptiva de la lengua española. Madrid: Espasa Calpe S.A.

Real Academia Española (2010). Nueva gramática de la lengua española. Manual. Madrid, Espasa Libros.

Soto R., C. (1993). Quechua: manual de enseñanza. (2ª Ed.). Lima, IEP. 